\title{
CONVERSION FACTORS OF THE TEMPERATURE EFFECT ON THE SHEAR STRENGTH OF ADHESIVELY-BONDED STEEL JOINTS
}

\author{
Hartmut PASTERNAK, Samer SAHELLIE \\ Department of steel and timber constructions, Faculty of Architecture, Civil Engineering and Urban Planning, \\ Brandenburg University of Technology, K.-Wachsmann-Allee 2, 03046 Cottbus, Germany
}

Received 23 Feb 2015; accepted 07 May 2015

\begin{abstract}
This paper presents the investigations on lap shear galvanized steel joints bonded by two structural adhesives (acrylic and epoxy) with two thicknesses of the bondline. The effect of the temperature on the shear strength of the adhesives when the joints are short-term-loaded is the main objective of the investigations. The partial factors of the limit states as well as the conversion factors that cover the use conditions and circumstances and particularly the temperature influence, within a temperature range from $-20{ }^{\circ} \mathrm{C}$ to $+40{ }^{\circ} \mathrm{C}$, are proposed. These factors are proposed by two methods commonly used in the respective standards; the direct evaluation method and prediction model-based method. A comparison between the results obtained by these methods is presented.
\end{abstract}

Keywords: structural adhesives, steel joints, partial factors, conversion factors, temperature effects, Bayesian method.

\section{Introduction}

Despite the advantages of the adhesive bonding technique, the structural designers, in the field of steel constructions, are still not able to use it in their practical applications because of the doubts regarding the verifiability of bonded steel joints. These doubts are mainly because of the lack of standards for verifying such joints in steel constructions and also the lack of describing the loss of strength and durability of adhesive materials due to the environmental effects, mainly temperature and humidity, and the long-term loading. Recently, efforts have been made to investigate the efficiency of bonding technique to be used in some applications in steel and aluminium structures (Pasternak, Meinz 2007, 2008; Piekarczyk, Grec 2012). These researches have shown that this technique is promising to be used in steel structures. However, for wider use, validation of the design rules for structural adhesive bonded joints according to the respective standards has to be done. Using allowable stress method in the design of adhesive joints has the disadvantage of not taking the statistical nature of both load actions and the resistance into account (Van Straalen et al. 1998). Consequently, fluctuating safety margins will be shown. The limit state concept, instead, can be used for considering the statistical nature with consistent safety margins.

The increase of temperature, according to some researches on adhesives, has detrimental influence on their properties such as ultimate strength (Osanai, Reis 2012;
Pasternak et al. 2012), elasticity modulus and stiffness (Cease et al. 2006). It results not only in change of the adhesive behavior from brittle into ductile, but also in change of the failure mode of bonded connections from cohesive to adhesive (Sahellie, Pasternak 2013). Moreover, adhesive materials can be considered as sensitive to the so-called rheological phenomena such as creep and shrinkage which may result in shortening of their durability (Majda, Skrodzewicz 2009; Boyes 1998). These effects have to be taken into consideration when designing the bonded joints by determining appropriate quantitative parameters.

This can be done by the use of the structural reliability method (Van Straalen 2001). This method guarantees the reliability level of the structure (the bonded joint) by taking into account the stochastic nature of the strengths of the joint components. It can also be used to validate a prediction model (analytical model) that describes the structural behavior of the bonded joints under prescribed conditions (Van Straalen, Van Tooren 2002; Pasternak, Ciupack 2014; Ciupack, Pasternak 2012).

In this paper, the partial factors as well as the conversion factor of the temperature effect on the shear strength of lap shear steel joints bonded by acrylic and epoxy adhesives are determined for two thicknesses of the bondline $0.35 \mathrm{~mm}$ and $0.65 \mathrm{~mm}$ and within a temperature range from $-20{ }^{\circ} \mathrm{C}$ to $+40{ }^{\circ} \mathrm{C}$. The representative values are determined by evaluating the tests results

Corresponding author: Hartmut Pasternak

E-mail: hartmut.pasternak@tu-cottbus.de 
data at different temperatures using the direct evaluation method according to ISO 2394:1998 (1998) and using prediction models that describe the change of the shear strength of the studied adhesives due to the temperature change following to the standard procedure recommended by EN 1990:2002 (2002) together with the systematic approach developed by Van Straalen (2001).

\section{Reliability-based evaluation for structures}

One of the evaluation methods, that is based on the structural reliability method, is the partial factor format which is commonly utilized to validate the use of structural materials and the design rules for structural applications. The strength of a structural material can be evaluated either directly from the test results (direct evaluation method), or by evaluating prediction models describing the change of the strength resulted from specific effects (analytical models-based evaluation). One of the methods that may be applied in the partial factor format is the Bayesian method which determines the representative values (characteristic and design values) of the strength values (ISO 2394:1998 1998). Accordingly, the partial safety factors and the conversion factors of the limit states can be estimated for an intended structural reliability level (EN 1990:2002 2002).

The limit state defines the condition beyond which the structure is no longer safe. It can be mathematically expressed by:

$$
Z=R-E
$$

in which, $R$ is the resistance and $E$ is the action effect.

If $Z>0$ (or $R>E$ ), then the structure is safe and no failure occurs. The reliability of the structure is validated when the highest predicted action effect is still less than or equal to the smallest predicted resistance over the intended lifetime of the structure. This can be expressed by the design and characteristic values of the action effect $E_{d}, E_{k}$ and of the resistance $R_{d}, R_{k}$ as shown in Eqn (2):

$$
E_{d} \leq R_{d} \text { or } \gamma_{E} \cdot E_{k} \leq \frac{\eta \cdot R_{k}}{\gamma_{R}},
$$

where $\gamma_{E}$ and $\gamma_{R}$ are the partial factors of the action effect and the resistance respectively which take the sto- chastic nature of the action effect and the resistance into account, while $\eta$ is the conversion factor that takes into account the change of the resistance over the lifetime intended.

The design and characteristic values of the action effect and the resistance have to be probabilistically and statistically determined at specific probabilistic fractiles. These values of the resistance, for example, could be taken at target probabilities of $5 \%$ and $0.1 \%$ respectively, further details are found in the mentioned standards.

\section{Shear by tension tests of adhesively-bonded steel joints}

\subsection{Studied joint}

Double lap shear joints, whose geometry shown in Figure 1, were selected. The common hot-dip galvanized steel $\mathrm{D} \times 51 \mathrm{D}+\mathrm{Z}(275)$ as classified in DIN EN 10327:2004 (2004) with thicknesses of 1 and $2 \mathrm{~mm}$ was selected to be the external and internal adherends, respectively. The investigated adhesives are the two-component cold-cure toughened acrylic DP 810 and epoxy DP 490. The bonded area for each side is $16 \times 16 \mathrm{~mm}$. Two thicknesses of the adhesive layer $(0.35$ and $0.65 \mathrm{~mm})$ were studied. These thicknesses were achieved by the use of one-sided adhesive strips, as shown in Figure 1.

The adhesives were applied according to the recommendations of the manufacturer $3 \mathrm{M}$ Scotch-Weld ${ }^{\mathrm{TM}}$. After bonding, the specimens were left at room temperature 7 days for epoxy and 5 days for acrylic adhesive to be cured.

\subsection{Test procedure}

The temperature range of $\left(-20{ }^{\circ} \mathrm{C}\right.$ to $\left.+40{ }^{\circ} \mathrm{C}\right)$ with a step of $10{ }^{\circ} \mathrm{C}$ was chosen for the investigations. Full cured bonded specimens were put in a climate chamber at the desired temperature for 24 hours. After 24 hours of conditioning, specimens were tested by means of tensile testing machine near to the climate chamber. The installation of a specimen up to the end of the test was done within 2 minutes. Temperature was measured using a laser thermometer at the surface of the specimen and only changed with a maximum of $2{ }^{\circ} \mathrm{C}$ after being installed in the testing machine out of the climate chamber. Seven specimens

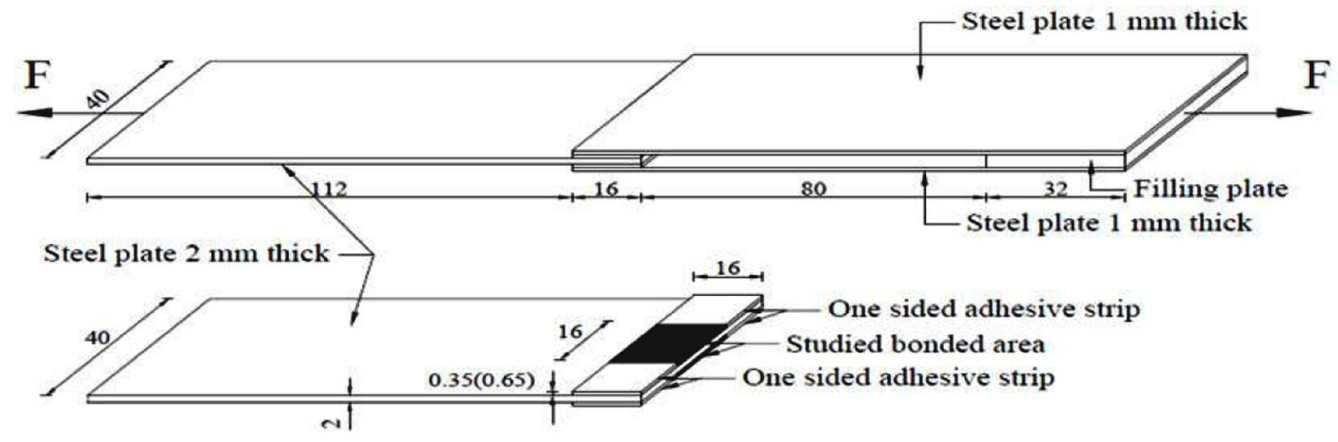

Fig. 1. Double lap shear joints black areas represent bonded areas 

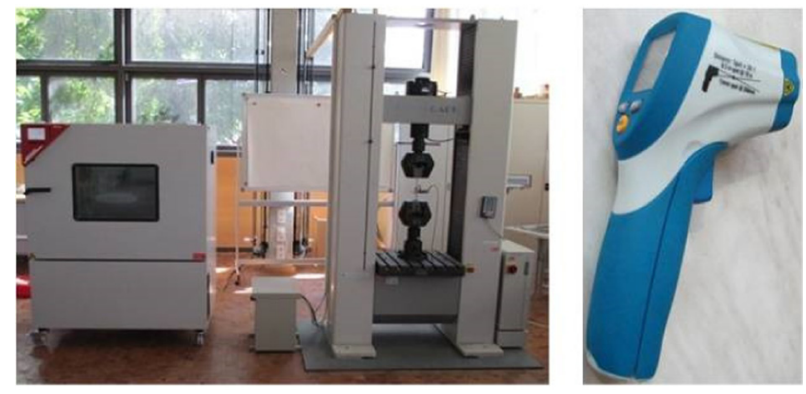

Fig. 2. Test equipment: left: the climate chamber close to the testing machine; right: the laser thermometer used for measuring the temperature at the surface of the specimen
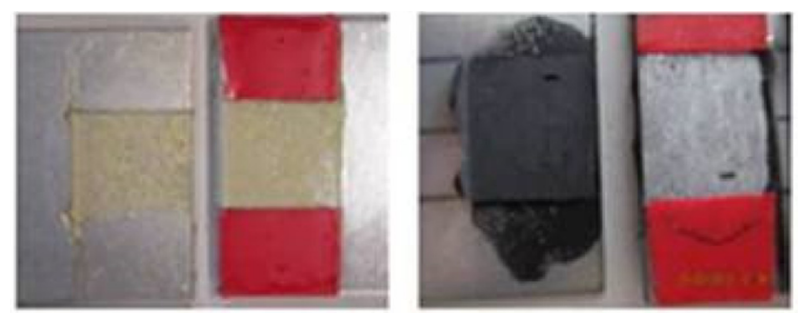

Fig. 3. Failure modes of AC (left) and EP (right)

for each temperature were tested; Figure 2 shows the climate chamber beside the testing machine and the laser thermometer used.

The speed rate of the crosshead was set to $1.27 \mathrm{~mm} /$ min. According to Wei et al. (2014), the overall strength of the joints has a close relationship with the average stress level of the adhesive layers. Hence, the shear stress was considered regularly distributed over the bondline and calculated by dividing the recorded applied force by the two-sided bonded areas, i.e. $2 \times 16 \times 16=512 \mathrm{~mm}^{2}$. It is worthwhile to mention that all specimens failed either cohesively (CF) or special cohesively (SCF) (EN ISO 10365:1995 1995), see Figure 3.

\subsection{Test results}

The mean and standard deviation values of the maximum shear strength of the adhesives are presented in Figure 4. These values were calculated after checking that the test results are normally distributed and excluding the outliers of each group at the studied temperatures. Anderson-Darling test (AD-test) was used for normality (Romeu 2005) and outliers (the extreme values do not appear to represent the populations) were detected by Z-test and discordance test (EPA QA 1998) as well as by Dixon extreme value test (Dixon 1950). It has to be mentioned that $\mathrm{AC} /$ EP indicate the acrylic/epoxy adhesives and $0.35 / 0.65$ indicate the bondline thickness investigated.

\section{Direct evaluation of the maximum shear strength values}

The resistance of the adhesively-bonded joints or the shear strength of the adhesives can directly be evaluated from the test results shown in Figure 4.

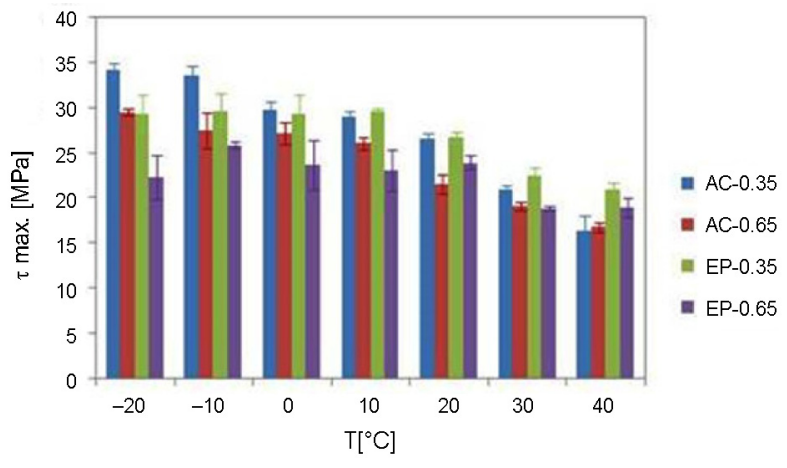

Fig. 4. Maximum shear stress of the adhesives over the temperature range studied

To determine the characteristic and design values of the maximum shear strength results, the Bayesian method was applied. Once these values have been determined, the corresponding partial factors can be estimated. This procedure was also followed by Van Straalen (2001). The characteristic and design values $R_{k}, R_{d}$ can be determined by Bayesian method using the following equations:

$$
\begin{aligned}
& R_{k}=\mu-t_{\mathrm{v}, k} \cdot \sigma_{R} \sqrt{\left(1+\frac{1}{n}\right)} ; \\
& R_{d}=\mu-t_{\mathrm{v}, d} \cdot \sigma_{R} \sqrt{\left(1+\frac{1}{n}\right)},
\end{aligned}
$$

in which: $\mu$ and $\sigma_{R}$ are the mean value and the standard deviation of the maximum shear strength of the adhesive. $t_{\mathrm{v}, k}$ and $t_{\mathrm{v}, d}$ represent the coefficients of the Student distribution to be used for estimating the characteristic and design values respectively. These coefficients depend on the target probability and the degree of freedom (v). In the absence of other information, the characteristic value is assumed to be at the target probability of 0.05 (ISO 2394:1998 1998). The design value can be taken at the target probability of $0.1 \%$ (Van Straalen 2001). The degree of freedom ( $v$ ) equals to $n-1$, where $n$ is the number of tests or the sample size.

The coefficients of the Student distribution for the desired degree of freedom (v) and the probability target can be determined by the use of Excel software or can be found in the literatures.

The characteristic and design values $R_{k}, R_{d}$ at each temperature for AC-0.35, AC-0.65, EP-0.35, and EP-0.65 were determined by Eqn (3) and Eqn (4) and listed in Table 1.

\subsection{Determination of the partial factor}

The partial factor $\left(\gamma_{R}\right)$ of the shear strength of the adhesives at room temperature $\left(20^{\circ} \mathrm{C}\right)$ can now be estimated using Eqn (5) and its values are 1.08, 1.29, 1.08, and 1.13 for AC-0.35, AC-0.65, EP-0.35, and EP-0.65, respectively.

$$
\gamma_{R}=\frac{R_{k}}{R_{d}} .
$$


Table 1. Characteristic and design values $R_{k}, R_{d}$ at each temperature resulted from direct evaluation method

\begin{tabular}{c|c|c|c|c|c|c|c|c}
\hline \multirow{2}{*}{$\begin{array}{c}\text { Temperature } \\
{\left[{ }^{\circ} \mathrm{C}\right]}\end{array}$} & \multicolumn{2}{|c|}{$\mathrm{AC}-0.35$} & \multicolumn{2}{c|}{$\mathrm{AC}-0.65$} & \multicolumn{2}{c|}{$\mathrm{EP}-0.35$} & \multicolumn{2}{c}{ EP-0.65 } \\
\cline { 2 - 9 } & $\begin{array}{c}R_{k} \\
{[\mathrm{MPa}]}\end{array}$ & $\begin{array}{c}R_{d} \\
{[\mathrm{MPa}]}\end{array}$ & $\begin{array}{c}R_{k} \\
{[\mathrm{MPa}]}\end{array}$ & $\begin{array}{c}R_{d} \\
{[\mathrm{MPa}]}\end{array}$ & $\begin{array}{c}R_{k} \\
{[\mathrm{MPa}]}\end{array}$ & $\begin{array}{c}R_{d} \\
{[\mathrm{MPa}]}\end{array}$ & $\begin{array}{c}R_{k} \\
{[\mathrm{MPa}]}\end{array}$ & $\begin{array}{c}R_{d} \\
{[\mathrm{MPa}]}\end{array}$ \\
\hline-20 & 32.61 & 29.78 & 28.48 & 26.19 & 25.13 & 18.39 & 17.12 & 9.02 \\
\hline-10 & 31.56 & 28.23 & 23.31 & 16.76 & 25.83 & 19.68 & 24.95 & 23.38 \\
\hline 0 & 27.52 & 23.56 & 24.62 & 20.63 & 24.95 & 18.03 & 17.87 & 8.72 \\
\hline 10 & 27.66 & 25.61 & 25.46 & 23.68 & 29.31 & 28.64 & 18.23 & 10.66 \\
\hline 20 & 25.46 & 23.68 & 19.15 & 14.88 & 25.44 & 23.46 & 22.31 & 19.80 \\
\hline 30 & 19.82 & 18.18 & 18.17 & 16.77 & 20.65 & 17.82 & 18.40 & 17.44 \\
\hline 40 & 12.67 & 6.87 & 15.45 & 13.15 & 19.14 & 17.14 & 16.80 & 13.45 \\
\hline
\end{tabular}

\subsection{Determination of the conversion factor}

In EN 1990:2002 (2002), the conversion factor that takes the additional effects such as the moisture, the temperature effects, etc. is defined by Eqn (6):

$$
R_{d}=\eta \frac{R_{k}}{\gamma_{R}}
$$

In our case, the design value at any temperature can be related to the design value at room temperature by the conversion factor $(\eta)$; therefore, $(\eta)$ can be estimated by dividing the design value at each temperature by its value at the room temperature. To cover all temperature range studied, the minimum value has to be considered. The values of $\eta$ are $0.29,0.88,0.73$, and 0.44 for $\mathrm{AC}-0.35$, $\mathrm{AC}-0.65$, EP-0.35, and EP-0.65 respectively.

\section{Evaluation of the maximum shear strength val- ues on the basis of an analysis model}

The above procedures were applied on small populations. Each one was considered at different temperature. The sample size, therefore, was of seven values as maximum (when no outliers detected). The risk of using such small sample size is when there is an extreme value relative to the rest values of the data set which is not detected by the "checking of outliers" tests. Hence, the parameters of the normal distribution used will be affected by these extreme values. This will normally result in getting a high scatterband that will surely affect the characteristic and design values as well as the partial factor accordingly calculated. To avoid having such problem, using larger populations that contain same features of the samples is recommended.

In our case, four larger populations were created by merging the data obtained for all temperatures. Each of them has the results of the specimens of the same adhesive material and the same thickness of the adhesive layer. These populations are: AC-0.35(M), AC-0.65(M), EP-0.35(M), and EP-0.65(M). The letter (M) indicates the merged data. Every population has from 46 to 49 values; depending on the number of the outliers excluded.
One of the methods to evaluate the results of the tests is the analysis model-based method that can be implemented by the procedures explained in EN 1990:2002 (2002), ISO 2394:1998 (1998). Van Straalen in his $\mathrm{PhD}$ study has also developed a systematic approach for reliable design rules for bonded joints (Van Straalen 2001). His approach is formulated to be used for all kinds of adhesive bonded joints under various actions and based on current knowledge about the behaviour of these joints and on structural reliability method.

The analysis models to describe these populations are formulated by considering that the maximum shear strengths are functions of the temperature, i.e. $\tau_{\max }=f(T)$; therefore, the mean values of $\left(\tau_{\max }\right)$ at each temperature versus the corresponding temperature $(T)$ were graphically plotted. The prediction models were then found by a regression analysis using Excel software as shown in Figure 5 (for AC-0.35(M) and $\mathrm{AC}-0.65(\mathrm{M})$ ) and in Figure 6 (for EP-0.35(M) and EP-0.65(M)).

In this work, to evaluate the test results by the proposed models, the methodology developed by Van Straalen (2001) was used.

The first step of the calibration process is to quantify the differences between the test values $R_{\text {test }, i}$ and the corresponding values calculated by the model $R_{\text {model }, i}$ for each data set by determining the multiplication factors $K_{i}$ for all data points using Eqn (7):

$$
K_{i}=\frac{R_{\text {test }, i}}{R_{\text {model }, i}} .
$$

New data sets of the calculated multiplication factors $K_{i}$ will have been obtained and can be statistically treated.

By applying the Bayesian method, the characteristic and design values of $K_{i}$ can be determined. Table 2 lists the characteristic and design values of $K_{i}$ for each population.

The characteristic and design values of the shear strength at each point can be calculated by Eqns (8) and (9). The results are summarized in Table 3. 


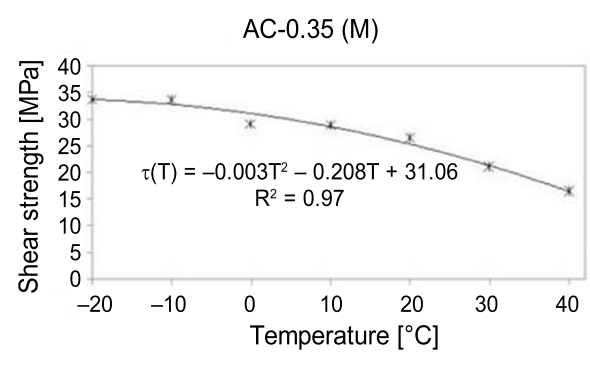

* Mean values —-Prediction model
AC-0.65 (M)

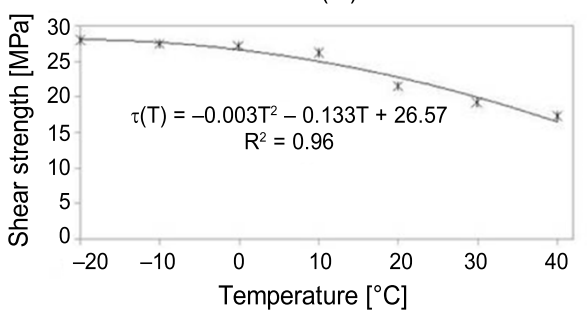

* Mean values _ Prediction model

Fig. 5. Shear strength vs. temperature for AC-0.35(M) and AC-0.65(M)
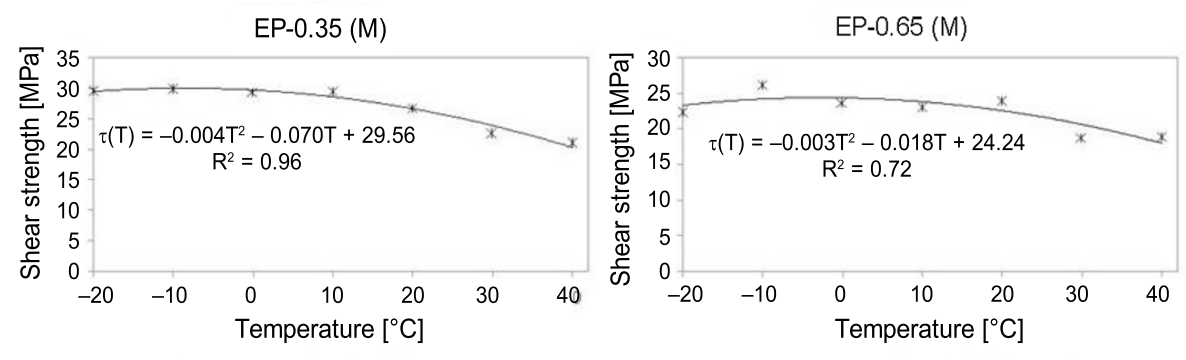

* Mean values — Prediction model

* Mean values _ Prediction model

Fig. 6. Shear strength vs. temperature for EP-0.35(M) and EP-0.65(M)

Table 2. Characteristic and design values of $K_{i}$

\begin{tabular}{l|c|c|c|c}
\hline & $\mathrm{AC}-0.35(\mathrm{M})$ & $\mathrm{AC}-0.65(\mathrm{M})$ & EP-0.35(M) & EP-0.65(M) \\
\hline Characteristic value $K_{k}[-]$ & 0.9 & 0.88 & 0.9 & 0.83 \\
\hline Design value $K_{d}[-]$ & 0.82 & 0.75 & 0.76 & 0.63 \\
\hline
\end{tabular}

Table 3. Characteristic and design values $R_{k}, R_{d}$ at each temperature resulted from analysis model-based evaluation method

\begin{tabular}{c|c|c|c|c|c|c|c|c}
\hline \multirow{2}{*}{$\begin{array}{c}\text { Temperature } \\
{\left[{ }^{\circ} \mathrm{C}\right]}\end{array}$} & \multicolumn{2}{|c|}{$\mathrm{AC}-0.35$} & \multicolumn{2}{c|}{$\mathrm{AC}-0.65$} & \multicolumn{2}{c|}{$\mathrm{EP}-0.35$} & \multicolumn{2}{c}{ EP-0.65 } \\
\cline { 2 - 9 } & $\begin{array}{c}R_{k} \\
{[\mathrm{MPa}]}\end{array}$ & $\begin{array}{c}R_{d} \\
{[\mathrm{MPa}]}\end{array}$ & $\begin{array}{c}R_{k} \\
{[\mathrm{MPa}]}\end{array}$ & $\begin{array}{c}R_{d} \\
{[\mathrm{MPa}]}\end{array}$ & $\begin{array}{c}R_{k} \\
{[\mathrm{MPa}]}\end{array}$ & $\begin{array}{c}R_{d} \\
{[\mathrm{MPa}]}\end{array}$ & $\begin{array}{c}R_{k} \\
{[\mathrm{MPa}]}\end{array}$ & $\begin{array}{c}R_{d} \\
{[\mathrm{MPa}]}\end{array}$ \\
\hline-20 & 30.62 & 27.90 & 24.67 & 21.02 & 26.42 & 22.31 & 19.42 & 14.74 \\
\hline-10 & 29.56 & 26.93 & 24.29 & 20.70 & 26.87 & 22.69 & 20.02 & 15.20 \\
\hline 0 & 27.95 & 25.47 & 23.38 & 19.93 & 26.60 & 22.47 & 20.12 & 15.27 \\
\hline 10 & 25.81 & 23.52 & 21.95 & 18.71 & 25.61 & 21.63 & 19.72 & 14.97 \\
\hline 20 & 23.13 & 21.07 & 19.98 & 17.03 & 23.90 & 20.19 & 18.82 & 14.29 \\
\hline 30 & 19.91 & 18.14 & 17.49 & 14.91 & 21.47 & 18.13 & 17.43 & 13.23 \\
\hline 40 & 16.15 & 14.71 & 14.48 & 12.34 & 18.32 & 15.47 & 15.54 & 11.79 \\
\hline
\end{tabular}

$$
\begin{aligned}
& R_{k, i}=K_{k} \cdot R_{\text {model }, i} ; \\
& R_{d, i}=K_{d} \cdot R_{\text {model }, i} .
\end{aligned}
$$

Determination of the partial and conversion factors: The partial factors $\left(\gamma_{R}\right)$ at room temperature $\left(20^{\circ} \mathrm{C}\right)$ and the minimum conversion factors $(\eta)$ that cover all temperature range studied were estimated by Eqns (5) and (6). The values of partial factors obtained are $1.10,1.17,1.18$, and 1.32 while the minimum conversion factors are $0.69,0.72,0.76$, and 0.82 for $\mathrm{AC}-0.35$, AC-0.65, EP-0.35, and EP-0.65 respectively. 


\section{Conclusions}

In this paper, the investigations on the temperature effect on the shear strength of two structural adhesives, used for bonding lap shear galvanized steel joints, were performed. Two thicknesses of the adhesive layer were used $0.35 \mathrm{~mm}$ and $0.65 \mathrm{~mm}$.

The temperature range investigated was from $-20{ }^{\circ} \mathrm{C}$ to $40^{\circ} \mathrm{C}$. The joints were tested under short-term-loading.

Two reliability-based methods were applied to evaluate the test results and to determine the partial factors of the limit states as well as the conversion factors of the shear strength of the adhesives.

Throughout the work, it was found that the partial factors, for AC-0.35, EP-0.35 and EP-0.65, obtained by the prediction model-based method are generally higher than those given by the direct evaluation method, however, for AC-0.65, a $10 \%$ higher value was recorded. Both methods proposed a partial factor of about (1.29-1.32) for the studied adhesives. The difference between the conversion factor values of both methods was noticed to be relatively high. However, the values of the prediction model-based method seem to be more convenient and realistic than those obtained by the direct evaluation method. This is mainly attributed to the sensitivity of the first method (direct evaluation method) to the extreme values which could not be detected as outliers to be excluded by the respective outlier tests; consequently, the determination of the design values was affected by the relatively large standard deviation of the scattered small samples at some temperatures. It is also clear that the conversion factor obtained by the first method is not necessarily corresponded to the highest temperature as shown for EP-0.65 (Table 1) which can also be explained by the large standard deviations of the samples tested at $-20^{\circ} \mathrm{C}$ and $0{ }^{\circ} \mathrm{C}$ (see Fig. 4).

Among the available literature, only one case (conversion factor values of EP-0.35) can be used for the sake of comparing the results of this work. The factors of EP-0.35 obtained by this work (0.73-0.76) were found to be in a good agreement when compared with the conversion factor proposed by Pasternak and Ciupack (2014), which is $(0.64)$, taking into consideration that the value of (0.64) was estimated for a different bondline thickness $(0.2 \mathrm{~mm})$ and a wider temperature range (from $-20^{\circ} \mathrm{C}$ up to $50{ }^{\circ} \mathrm{C}$ ).

As a conclusion for all cases studied in this work, the direct evaluation method proposes a conversion factor of the temperature effect of 0.29 while the prediction model-based method proposes a more convenient value which is 0.69 .

\section{Acknowledgements}

This work was carried out under the financial support provided by the German Academic Exchange Services (DAAD).

\section{References}

Boyes, R. 1998. Adhesive bonding of stainless steel: strength and durability: $\mathrm{PhD}$ thesis. Sheffield Hallam University, UK.

Cease, H.; Derwent, P.; Diehl, H.; Fast, J.; Finley, D. 2006. Measurement of mechanical properties of three epoxy adhesives at cryogenic temperatures for CCD construction. Fermi National Accelerator Laboratory, Fermilab-TM2366-A, Batavia. 19 p.

Ciupack, Y.; Pasternak, H. 2012. Calibration of design rules in accordance with Eurocode using the example of adhesive joints, Bauingenieur 87: 116-123.

DIN EN 10327:2004. Continuously hot-dip coated strip and sheet of low carbon steels for cold forming. DIN Deutsches Institut für Normung e.V. Berlin, 2004. 25 p.

Dixon, W. J. 1950. Ratios involving extreme values. Contract N6-onr-218/IV with the office of Naval Research. University of Oregon.

EN 1990:2002. Eurocode - Basis of structural design. European Committee for Standardization. Brussels, 2002. 119 p.

EN ISO 10365:1995. Adhesives - Designation of main failure patterns. European Committee for Standardization. Brussels, $1995.5 \mathrm{p}$.

ISO 2394:1998. General principles on reliability for structures. International Organization for Standardization. Geneva, 1998.

Majda, P.; Skrodzewicz, J. 2009. A modified creep model of epoxy adhesive at ambient temperature, International Journal of Adhesion and Adhesives 29(4): 396-404. http://dx.doi.org/10.1016/j.ijadhadh.2008.07.010

Osanai, K. R.; Reis, M. L. 2012. Temperature effect on the strength of adhesively bonded single lap joints, Engenharia Térmica [Thermal Engineering] 11(1-2): 3-6.

Pasternak, H.; Ciupack, Y. 2014. Development of Eurocodebased design rules for adhesive bonded joints, International Journal of Adhesion and Adhesives 53: 97-106. http://dx.doi.org/10.1016/j.ijadhadh.2014.01.011

Pasternak, H.; Meinz, J. 2007. Adhering in steel construction advantages and possibilities, in Proc. of the $9^{\text {th }}$ International Conference "Modern Building Materials, Structures and Techniques”, 16-18 May 2007, Vilnius, Lithuania. $10 \mathrm{p}$.

Pasternak, H.; Meinz, J. 2008. Adhesive bonding - a promising joining technique also in steel construction, in The $5^{\text {th }}$ International Conference on Thin-Walled Structures, 18-20 June 2008, Brisbane, Australia, 1: 67-74.

Pasternak, H.; Ciupack, Y.; Dilger, K.; Hanssen, E. 2012. Entwicklung eines Eurocode-basierten Bemessungskonzepts für Klebverbindungen im Stahlbau (in Anlehnung an DIN EN 1990). IGF-Vorhaben: 16494 BG-FOSTA P 827, Final report, Germany.

Piekarczyk, M.; Grec, R. 2012. Application of adhesive bonding in steel and aluminium structures, Archives of Civil Engineering 58(3): 309-329.

http://dx.doi.org/10.2478/v.10169-012-0018-8

Romeu, J. L. 2005. Anderson-Darling: a goodness of fit test for small samples assumptions, START (Selected topics in Assurance Related Technologies) 10(5): 1-6.

Sahellie, S.; Pasternak, H. 2013. Temperature effect on mechanical behaviour of adhesive bonded steel joints under short and long-term loading, in the $13^{\text {th }}$ International Scientific Conference (VSU'2013), 6-7 June 2013, Sofia, Bulgaria, 2: 7-12.

United States Environmental Protection Agency (EPA QA). 1998. Guidance for data quality assessment - practical methods for data analysis. EPA QA/600/R-96/084 (QA 97 version). 
Van Straalen, I. J. 2001. Development of design rules for structural adhesive bonded joints - a systematic approach: $\mathrm{PhD}$ thesis. Netherlands Delft University of Technology.

Van Straalen, I. J.; Van Tooren, M. L. 2002. Development of design rules for adhesive bonded joints, Heron 47(4): 263-274.

Van Straalen, I. J.; Wardenier, J.; Vogelesang, L. B.; Soetens, F. 1998. Structural adhesive bonded joints in engineering - drafting design rules, International Journal of Adhesion and Adhesives 18(1): 41-49.

http://dx.doi.org/10.1016/S0143-7496(97)00068-7

Wei, X.; Huichen, Y.; Chunhu, T. 2014. Influence of randomly distributed adhesive properties on the overall mechanical response of metallic adhesively bonded joints, International Journal of Adhesion and Adhesives 52: 48-56. http://dx.doi.org/10.1016/j.ijadhadh.2014.04.001

Hartmut PASTERNAK. Prof. Dr-Ing. habil., Brandenburg University of Technology). He is involved in teaching, research and design of steel structures for more than 25 years. He is member in several National and International Committees (e.g. full member of the ECCS Technical Committee 8 "Structural Stability", member of German subcommittee DASt-Ri015 "Girders with thin webs", member of COST C25 action "Sustainability of Constructions", member of the working group Eurocode 3 "Crane supporting structures"). He has participated in numerous research projects (e.g. on thin-walled members, welding stresses and adhesive bonded joints). Under his supervision $10 \mathrm{PhD}$ 's were completed. He has more than 130 publications in Journals and at Conferences and is co-author of books in German (4) and English (1) on steel structures. Moreover he is the editor of the journal "Bauingenieur" for steel structures.

Samer SAHELLIE. Dr.-Ing., Brandenburg University of Technology, Germany. He is a scientific assistant at the Department of Structural Engineering, Tishreen University, Syria. His research interests include adhesive-bonded joints in lightweight steel constructions, strength and behaviour of materials, structural modeling and analysis, building design and construction, rehabilitation of steel and concrete structures. 